\title{
Retos del diseño arquitectónico, urbano y paisajista dentro de los nuevos modelos económicos
}

\section{Challenges of architectural, urban and landscape design within the new economic models}

\section{Laura Chaverri-Flores ${ }^{1}$}

Chaverri-Flores, L. Retos del diseño arquitectónico, urbano y paisajista dentro de los nuevos modelos económicos. Tecnología en Marcha. Edición especial. Escuela de Arquitectura y Urbanismo, Diciembre 2020. Pág 102-117.

doi) https://doi.org/10.18845/tm.v33i8.5513 


\section{Palabras clave}

Arquitectura del paisaje; Diseño como mercancía; centros comerciales; neoliberalismo; derecho a la ciudad.

\section{Resumen}

En nuestra sociedad capitalista contemporánea existe una tendencia a la autodestrucción respaldada por el dominio del ser humano sobre la naturaleza. Los parques nacionales, las ciudades y la arquitectura se han convertido en objetos de consumo. El objetivo de este trabajo es identificar consecuencias, retos y alternativas para el diseño urbano, paisajístico y arquitectónico en el sistema económico neoliberal. En cuanto a la metodología, se realizaron diferentes revisiones bibliográficas de autores de diversas disciplinas como la economía, la geografía y la arquitectura, y en particular ciertas obras de Franz Hinkelammert, quien compara el capitalismo con una nueva religión del mercado que conlleva a la autodestrucción. Además, se ejemplifica la argumentación con algunos casos de estudio concretos y se genera un diálogo y reflexión en torno a la repercusión que ha tenido el sistema económico neoliberal en la ciudad y el paisaje, donde la propiedad privada se encuentra por encima del espacio público. Se realiza un análisis de los centros comerciales que simbolizan los nuevos templos de la religión neoliberal. Dentro de los resultados y discusión se recopilan las consecuencias, pero se exploran viejos paradigmas olvidados como alternativas, asimismo la posibilidad de utilizar el diseño como bien común. Algunas de las conclusiones finales revelan la dependencia del diseño con la forma de pensar del diseñador, quien podría generar innovaciones. Se revisan algunas resistencias al sistema imperante como la arquitectura resiliente, y se evidencia la urgencia de un cambio de paradigma de la sociedad actual.

\section{Keywords}

Landscape architecture; Design as merchandise; shopping centers; neoliberalism; right to the city.

\footnotetext{
Abstract

In our contemporary capitalist society, there is a tendency to self-destruction backed by human domination over nature. National parks, cities, and architecture have become objects of consumption. The objective of this work is to identify consequences, challenges, and alternatives for urban, landscape, and architectural design in the neoliberal economic system. Regarding the methodology, different bibliographic reviews were carried out considering authors from various disciplines such as economics, geography, and architecture, particularly some works by Franz Hinkelammert that compares capitalism with a new market religion that leads to self-destruction. Also, the argument is exemplified with some specific case studies along with generated dialogue and reflection around the impact that the neoliberal economic system has had on the city and the landscape, where private property is above public space. An analysis of the shopping malls symbolizing the new temples of the neoliberal religion is carried out. The results and discussion collect the consequences but explore old forgotten paradigms as alternatives, as well as the possibility of using design as a common good. Some of the findings reveal the reliance upon the design with the designer's way of thinking, who could generate innovations. Some resistances to the prevailing system like resilient architecture are reviewed, and the urgency of a paradigm shift in today's society is evident.
} 


\section{Introducción}

Los siglos XIX y XX se caracterizaron por ser épocas de transformación y búsqueda de nuevos tipos de expresión en el mundo mecanicista occidental, donde imperaba el dominio del ser humano sobre la naturaleza. El poder del pensamiento y de la razón llega a su máxima expresión con el paradigma mecanicista, caracterizado por ser cuantitativo, reduccionista, patriarcal y antropocéntrico [1, p. 20-21].

El ser humano en su incansable deseo de progreso no "pensó" en el daño que le provocaba a su entorno. Dicha agresión tiene una multitud de rostros; entre ellos: la deforestación, la destrucción de la capa de ozono, el efecto de invernadero, y la contaminación principalmente. Además, se ha contribuido a la extinción de pueblos indígenas y especies a través de la sistemática destrucción de hábitats, bosques y complejos biológicos, agravando el desequilibrio ecológico de sus territorios.

Es así como en la sociedad capitalista actual, existe una tendencia a la autodestrucción del ser humano. Por un lado, se descubren nuevas medicinas para curar enfermedades mortales, pero por otro se generan bombas atómicas y armas nucleares que podrían acabar con el planeta en poco tiempo. En los últimos años, las consecuencias y amenazas del "progreso" han sido reveladas por científicos e investigadores. Sin embargo, ha dominado más fuertemente el anhelo por el poder y el consumo que nos ha llevado a esta autoeliminación. Para Franz Hinkelammert [1]: "No se trata de una reacción en contra del progreso, sino de una duda cada vez mayor en cuanto a las consecuencias del progreso hasta para la propia vida humana" [2, p. 1].

Según la visión del paradigma mecanicista y el sistema económico neoliberal, la ciencia y la tecnología ayudan al hombre a mejorar "su condición de vida" pero, ¿a qué precio?: armamentismo, producción industrial, contaminación de suelos y agua, creciente gasto de energía. Además, con esto: ¿qué entendemos como calidad de vida?, ¿vivir en ciudades fragmentadas con grandes avances tecnológicos y donde lo natural parece inalcanzable?

El objetivo de este trabajo es identificar consecuencias, retos y alternativas para el diseño urbano, paisajístico y arquitectónico en el sistema económico neoliberal. Se abordará la repercusión que ha tenido este sistema económico, convirtiéndose en la nueva religión del mercado y borrando los derechos a la ciudad y a la vida. Además, se explorará cómo el diseño, la ciudad y el paisaje se han transformado en una mercancía, y como los centros comerciales simbolizan los nuevos templos de este culto. Asimismo, se analizarán los esfuerzos de recuperar el derecho a la ciudad y al paisaje para finalizar con alternativas de cambio de paradigma y resistencia en contra de esta religión del suicidio colectivo.

\section{Materiales y métodos}

Al ser una investigación de carácter cualitativo, en primera instancia se realizaron diferentes revisiones bibliográficas de autores de diversas disciplinas como la economía, la geografía y la arquitectura, haciéndose énfasis en el trabajo de Franz Hinkelammert, economista y teólogo alemán reconocido en el mundo por sus obras de crítica del neoliberalismo, quién compara el capitalismo con una nueva religión del mercado que conlleva a la autodestrucción. En este recorrido teórico, se identificaron consecuencias, retos y alternativas actuales, para el diseño urbano y paisajístico en este contexto económico.

Se ejemplificó la teoría con casos de estudio concretos de Costa Rica y otras latitudes, apoyados por fotografías, generando un diálogo y reflexión en torno a la repercusión que ha tenido el sistema económico neoliberal en la ciudad y el paisaje. Finalmente, se realizó un análisis de los centros comerciales contemporáneos en la ciudad, centrado en su similitud 
simbólica con los templos religiosos. Se utilizaron estudios de caso, y revisiones bibliográficas, para respaldar la hipótesis de visualizar los centros comerciales como los nuevos templos de la religión neoliberal.

\section{Consecuencias del sistema económico neoliberal}

\section{La religión neoliberal del mercado}

Franz Hinkelammert acota que: "El capitalismo extremo es un capitalismo suicida, sin que esta tendencia suicida sea algún proyecto de aquellos, que tienen el poder sea económico o político" [2, p. 5]. En este sistema, todas las decisiones giran en torno a la maximización de la ganancia [2, p. 5] y los valores que tiene nuestra sociedad capitalista no son capaces de detener este suicidio colectivo [2, p. 7]. Por ende, en esta estructura es donde se generarán más ganancias y no en actitudes alternativas, al punto de tornarse sagrada: "El capitalismo mismo es religión de los fetiches, que Marx también llama religión de los dioses terrestres" [2, p. 15].

Con esta religión, los Estados se desmantelan y se enmarca la filosofía de la privatización de la educación, salud y servicios, entre otros. Ahora, quien no pueda pagar sus medicamentos simplemente muere. Cientos de personas sin hogar mueren en los países europeos y en Estados Unidos, con los fríos tan intensos que los azotan en invierno por no tener un techo que los proteja. Con el pensamiento neoliberal de la extrema derecha, no se ve necesario tampoco, auxiliar a los refugiados.

Sin embargo: "El ser humano no es para el capital y su maximización de las ganancias, sino que el capital es para el ser humano" [3, p. 21]. El autor nos explica cómo esta premisa expuesta por Marx, se ha convertido en lo opuesto con la religión del mercado, transformándose el ser humano en mercancía y desvalorizando tanto su vida como la de su entorno natural. Entonces nos preguntamos, ¿Cómo proteger la vida tanto humana y del planeta ante esta religión autodestructiva?

\section{La Ciudad y el paisaje como mercancía}

Otra de las consecuencias del sistema económico neoliberal es concebir la ciudad y el paisaje como mercancía. Con respecto al paisaje "natural" y cultural, Herbert Marcuse [3], en su libro El hombre Unidimensional nos comenta:

"Paseo por el campo. Todo está como debe de ser: la naturaleza en todo su esplendor. Los pájaros, el sol, la hierba, la vista de las montañas a través de los árboles, nadie alrededor, ninguna radio, ni olor a gasolina. Entonces el sendero tuerce y termina en la autopista. Estoy otra vez entre los anuncios, las gasolineras, los moteles y los albergues de carretera. Estaba en un parque nacional y ahora sé que esto no era realidad. Era una «reserva», algo que se conserva como una especie en vías de desaparición. Si no fuera por el gobierno, los anuncios, los puestos de hot dogs y los moteles hubieran invadido hace mucho ese fragmento de naturaleza. Le estoy agradecido al gobierno; estamos mucho mejor que antes..." [4, p. 255]

El paradigma dominante habla del dominio del ser humano sobre la naturaleza, en contradicción a la armonía con la misma que promueven otras culturas. Se ve al ambiente como un recurso para los humanos. Se cree en el consumismo, el "progreso" y las soluciones de alta tecnología en contraposición a vivir con lo suficiente, el reciclaje y la eficiencia.

En Costa Rica, conocido como el país más biodiverso del mundo por kilómetro cuadrado, se ha transformado la naturaleza en urbanidad, creando ilusiones encerradas en parques, que nos recuerdan esta riqueza. Se inventa al costarricense como un ser "ecológico" por encarcelar en 
parques nacionales parte de las áreas verdes que nos quedan, comercializando de esta forma nuestra naturaleza y oponiéndola al paisaje de la ciudad, dominado por propiedades privadas desprovistas de vegetación.

Mi pregunta sería: ¿Cómo podemos solucionar esta contradicción mental del costarricense, que no valora la gran riqueza ecológica que lo rodea? En este contexto, el progreso, significa construir el $100 \%$ del terreno y desdibujar la selva tropical que alguna vez existió, generando parques con estilos europeos y negando el trópico.

En los años setenta el gobierno de Costa Rica comenzó con la creación de una Red de Parques Nacionales, con fines de conservación. Sin embargo, estos parques se convirtieron en un objeto de marketing y de atracción turística en donde se comercializa la naturaleza. Parecido a un zoológico, se conformaron islas naturales a lo largo del país sin tomar en cuenta la conectividad necesaria para el traslado de fauna y los cuerpos de agua. Por eso, es común encontrar en nuestro país parques segregados por una carretera nacional, provocando diariamente la muerte de animales que intentan cruzar la calle. Por ejemplo, el Parque Nacional Carara, donde convergen diversidad de especies tanto del bosque seco como húmedo que se encuentra dividido por la carretera-ruta 34, Pacífica Fernández (figura 1). Además, se encuentra a tan solo 2 kilómetros del río Grande de Tárcoles, uno de los ríos más contaminados de Centro América.

Paradójicamente, mientras un espacio natural para el turismo se conserva y se explota, a pocos kilómetros el excepcional río constituye la cloaca de las aguas negras provenientes del Valle Central, poniendo en peligro la vida de los cocodrilos, e importante cantidad de fauna que resiste a la contaminación gracias a la presencia del Manglar Guacalillo todavía no "explotado" por el turismo. En este caso, el "mercado decide legítimamente sobre vida y muerte" [3, p. 21]; no solo de los seres humanos sino también de la flora y la fauna, y de hasta la vida de un río. Sin embargo, aunque históricamente ha sido a través del Estado que se han gestado la conservación de espacios naturales y la creación de espacios públicos como parques urbanos, estas acciones no son suficientes para la conservación natural pues es imprescindible la conectividad.

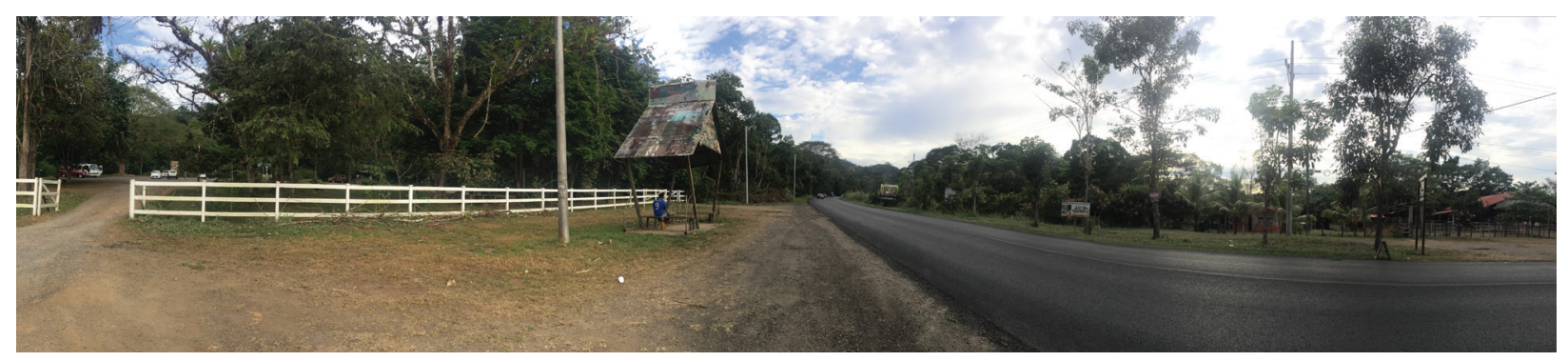

Figura 1. Vista de acceso al Parque Nacional Carara desde carretera 34.

Lo anterior es sumamente irracional, pero es lo natural en el mercado: "El pensamiento de Smith es un pensamiento sin derechos humanos y en este sentido sin ética, en el cual todos los derechos que el ser humano tiene, son derechos correspondientes al mercado. Por tanto, son derechos de propiedad" [3, p. 27]. Desde la revolución francesa se ha gestado una reducción de los derechos humanos dirigida "a un ser humano más bien abstracto, sobre todo propietario, masculino y de explotación extrema, inclusive con el trabajo forzado de la esclavitud” [3, p. 28].

No es de extrañar entonces, que se haya excluido al pobre, al negro, al indígena, a la mujer, al discapacitado entre otros de esta "igualdad" utópica. Desde esta perspectiva, queda la duda 
si el circuito de movilidad universal creado en el Parque Nacional Carara, es una estrategia de derechos humanos, dándole la oportunidad al ser humano que no puede caminar o ver, a ser parte de este espacio, o más bien es una estrategia más de mercado (figura 2). En este sentido, si realmente el derecho a transitar o ser parte de un bosque tropical son derechos de mercado, no estaría mal que este mercado valorice en el diseño urbano y de paisaje la naturaleza, la inclusividad, los árboles, en lugar de las carreteras, la homogeneidad humana y la ciudad de concreto.

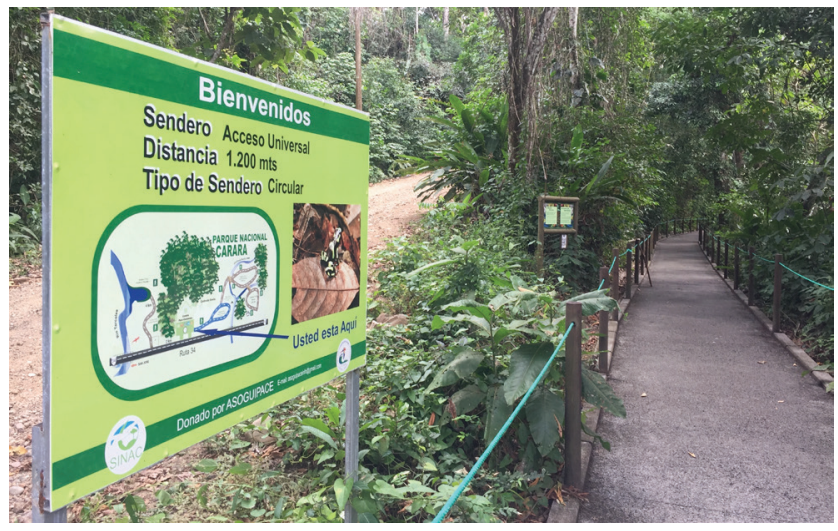

Figura 2. Vista de sendero acceso universal. Parque Nacional Carara desde carretera 34.

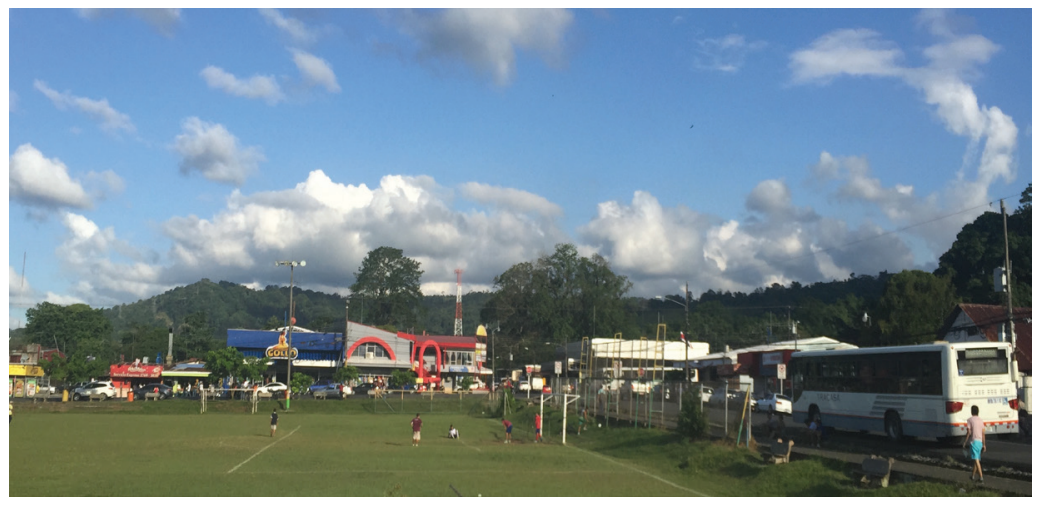

Figura 3. Calle en Siquirres.

Agradecerle irónicamente al gobierno como hace Marcuse, sobre este paisaje no invadido, sobre este oasis entre los rótulos y comercios es una opción ingenua. Sin embargo, desde la visión conservacionista se debe ir más lejos, y potenciar la vida natural en la ciudad. Paradójicamente, en Costa Rica nuestros pequeños centros urbanos, en lugar de potenciar el valor del paisaje de cada zona (que podría por cierto generar ganancias desde el marketing del turismo ecológico), son invadidos por diferentes negocios que homogenizan e impermeabilizan los paisajes. Es así como la calle comercial de Siquirres (figura 3), no va a ser muy diferente a la de Parrita, dominadas por un gran almacén Gollo, Palí, Importadora Monge, y esos grandes negocios que no varían arquitectónicamente en climas desde 20 a 35 grados. En estas calles comerciales domina el Dios neoliberal del mercado, de la política, de la globalización, entendido por Hinkelammert [3], como el Dios de la privatización y del capitalismo productivo [3, p. 47]. 
Para David Harvey [5]:

La calidad de la vida urbana se ha convertido en una mercancía, como la ciudad misma, en un mundo en el que el consumismo, el turismo, las industrias culturales y las basadas en el conocimiento se han convertido en aspectos esenciales de la economía política urbana [5, p. 31]. Como consecuencia, algunos diseños arquitectónicos, se fundamentan en nuevos estilos de vida desde la estrategia de mercado, ofreciendo por ejemplo condominios para deportistas, con todo lo que un club deportivo pueda ofrecer, o complejos habitacionales con todos los servicios como guarderías y supermercados; en donde los inquilinos encerrados en una burbuja no tengan contacto con el resto de las poblaciones. De esta manera, los ríos y los grandes muros dividen estilos de vida muy diferentes.

\section{Los Centros Comerciales como los nuevos templos religiosos}

Con la conquista de América, la iglesia fue el símbolo de poder arquitectónico más importante. Aprovechando la ubicación sagrada de los templos indígenas, muchas iglesias fueron construidas encima de estos. En nombre del Dios cristiano, se asesinó, se destruyó y se impuso una manera de pensar y de hacer ciudad, en donde las iglesias monumentales, bañadas en oro modificaban el paisaje histórico. El poeta antillano, Aimé Cesaire [6] afirma que la colonización deshumaniza, para él la empresa colonial "tiende inevitablemente a modificar a aquel que la emprende; que el colonizador, al habituarse al ver en el otro la bestia, al ejercitarse en tratarlo como bestia, para calmar su conciencia, tiende objetivamente a transformarse el mismo en bestia" [6, p. 19].

Por lo tanto, gracias a la conquista, nace en América la intolerancia, el racismo exacerbado y la desigualdad tanto territorial como social. Desde el punto de vista territorial, fue en este periodo en donde se conformaron los barrios divididos por etnia. De esta forma en Cartago de Costa Rica, por ejemplo, existió la ciudad de españoles y los pueblos de mulatos y de indios, como fue el caso de Orosi. Todos estos territorios poseían una iglesia y su tamaño variaba simplemente, según la jerarquía del poblado.

Actualmente muchas iglesias ya no son tan visitadas, pero se han convertido en un lugar de visitación turística. Por ejemplo, para acceder a la Catedral de Santa María del Fiore en Florencia, se debe comprar un tiquete de aproximadamente 15 euros (incluye varios edificios del conjunto monumental del Duomo de Florencia), y luego realizar una larga fila para observar el monumento en fila india junto con otros turistas. El Oratoire de San Joseph en Montreal, recibe por su parte, 2 millones de visitantes al año. Como parte del conjunto, posee una gran tienda de regalos y es posible realizar una visita guiada por un costo de 5 dólares canadienses y hasta realizar compras en línea (figura 4 y 5). Vemos con estos ejemplos, otra consecuencia de este sistema económico, donde los comercios comienzan a invadir estos espacios, transformando también ideologías y fortaleciendo la hipótesis del capitalismo extremo y la capitalización de la ganancia.

En la actualidad, muchos han dejado de visitar los templos los domingos y en su lugar el centro comercial se ha vuelto el lugar de peregrinación. Este "no lugar", en general se ubica en cualquier sitio a las afueras de la ciudad y posee distribuciones iguales en casi cualquier lugar del mundo. Para Beatriz Sarlo [7]: "La ciudad no existe para el shopping, que ha sido construido para remplazar a la ciudad" [7, p. 3]. Los centros comerciales no se integran al contexto urbano y viven hacia adentro, su arquitectura no varía según condición climática o la cultura: "Como en los casinos de Las Vegas (y los shoppings aprendieron mucho de Las Vegas), el día y la noche no se diferencian: el tiempo no pasa, o el tiempo que pasa es también un tiempo sin cualidades" [7, p. 3]. Con la globalización, es común encontrar las mismas tiendas, la misma distribución arquitectónica, las mismas películas en los cines, en los diferentes países. 
No puede faltar un McDonald's, una tienda Nike, o un cine con un estreno hollywoodense. Para Sarlo [7], Ios centros comerciales se han extendido drásticamente, generándose este tipo de espacios en hospitales, aeropuertos y hasta escuelas. "Se nos informa que la ciudadanía se constituye en el mercado y, en consecuencia, los shoppings pueden ser vistos como los monumentos de un nuevo civismo: ágora, templo y mercado, como en los foros de la vieja Italia romana" [7, p. 3]. El Dios Mercado o Dinero, ahora también modifica modos de vida y cultura, globalizando comportamientos y conductas consumistas. "Los puntos de referencia son universales: logotipos, siglas, letras, etiquetas, no requieren que sus intérpretes estén afincados en ninguna cultura previa o distinta de la del mercado" [7, p. 4].

Desde esta expansión de los centros comerciales a espacios inicialmente pensados para otros usos, el aeropuerto de Panamá es un buen ejemplo. Como la mayoría de aeropuertos del mundo posee una importante cantidad de espacios para la venta libre de impuestos. Llama la atención que, entre los licores, perfumes, casas de cambios y lugares de masajes, se encuentra un templo religioso, con la misma jerarquía: la Capilla de Nuestra Señora de Loreto (figura 6).

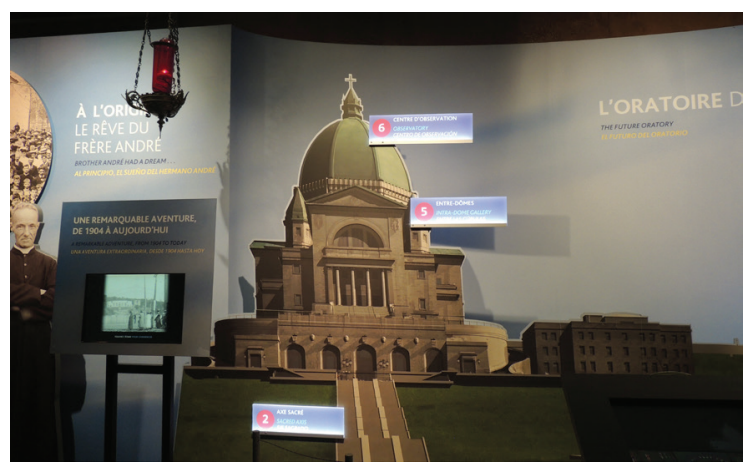

Figura 4. Foto de afiche informativo en Oratoire de Montreal.

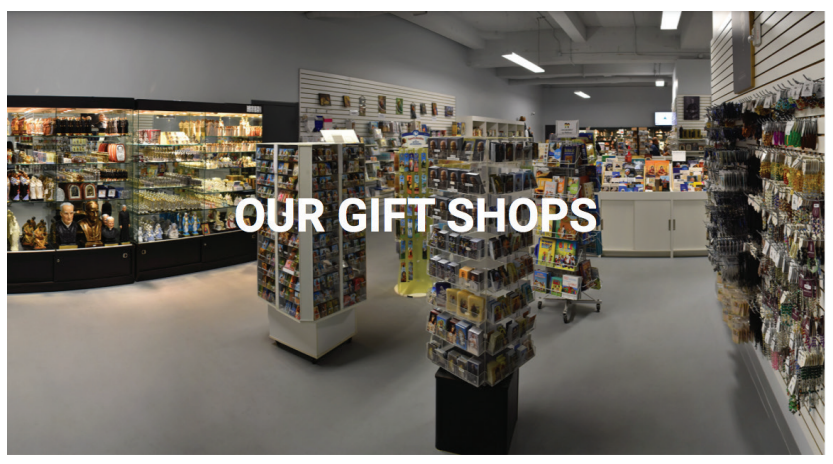

Figura 5. Foto de tienda de regalos del Oratoire. Fuente: Saint Joseph Org [8]. 


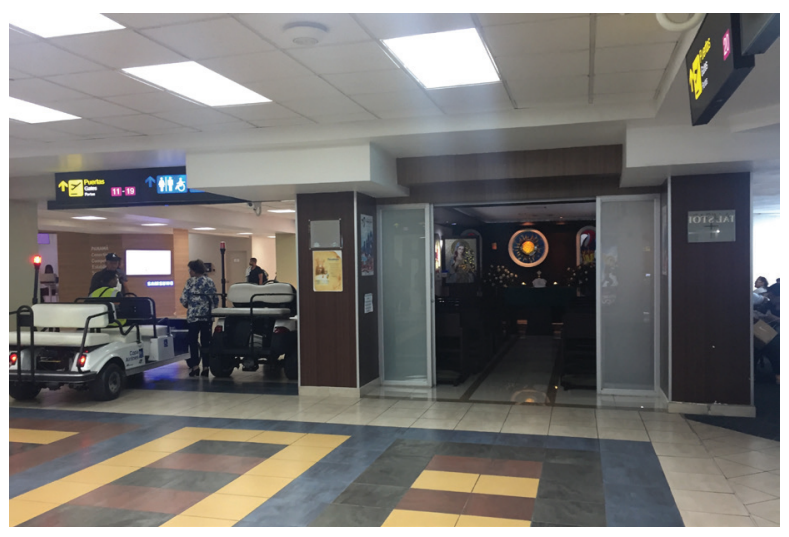

Figura 6. Foto de templo religioso en Aeropuerto de Tocumen.

Con la inmersión de Grecia a la Unión Europea, este país se transformó en una especie de colonia de esta última, que debe seguir las órdenes del mercado, que se le soliciten. Una de las exigencias por parte de los países afiliados fue que se abrieran los centros comerciales los domingos. En la ley del "Dios Dinero" el trabajo se debe generar todos los días y a todas horas. El tiempo como dicen por ahí, es dinero, y por lo tanto se vive en una sociedad que venera la rapidez y la eficiencia. Además, tomando en cuenta que el gasto que se realiza en los centros comerciales es proporcional al tiempo de visitación del mismo, las grandes empresas han invertido en las actividades lúdicas y festivas para retener a sus consumidores [9, p. 84].

Un ejemplo extremo de la nueva forma de concebir la ciudad y sus nuevos templos en el capitalismo es la ciudad de Dubai. Existen más de 45 centros comerciales, y las compras son la actividad principal. La ciudad misma representa un inmenso centro comercial, por lo que existe una ausencia de inversión en los espacios públicos [9, p. 87, 88].

\section{Disminución del derecho a la ciudad}

Según Hinkelammert [3], en la actualidad han vuelto a surgir posiciones "anti-humanistas" de los fascistas de los años 20. Sin embargo, ya no se trata de un pensamiento desde las masas o del Estado, sino del mercado y de las grandes burocracias de las empresas privadas [3, p. 33], si no que estas "burocracias ahora dominan la gran mayoría de los medios de comunicación" [3, p. 33], controlando de esta forma la libertad de opinión.

Para este autor [3], el neoliberalismo elimina los derechos humanos, en donde "todos los seres humanos tienen derecho de propiedad, pero ningún derecho de poder vivir... Pero aquella persona que no tiene propiedades no tiene ningún derecho... Hay que dejar morir." [3, p. 35]. Desde esta visión de los neoliberales, dejar morir no es sinónimo de matar, por lo que las hambrunas, guerras y muertes son necesarias para la preservación de otras vidas. En este contexto, la propiedad privada se encuentra por encima del espacio público. No es de extrañar entonces, la actitud de nuestros ciudadanos que encierran sus viviendas con alambres navajas, tal como un campo de concentración, sin ninguna preocupación por el bien común.

Para Jorge Vergara Estévez [10], las políticas neoliberales no han producido la prosperidad para todos pronosticada por Hayek, sino lo opuesto: "el aumento de la desigualdad y de la distribución regresiva del ingreso; aumento de propiedad de los multimillonarios que excede el crecimiento del PIB de los países" [10, p. 203]. En este sentido, para este autor la concepción neoliberal está en crisis [10, p. 202]. 
Para Harvey [5]:

El giro neoliberal ha restaurado el poder de clase en manos de las élites ricas. En México han aparecido 14 mil millonarios desde entonces, y en 2006 el país se jactaba de que un connacional, Carlos Slim, era el hombre más rico del planeta, al tiempo que las rentas de los pobres se habían estancado o directamente disminuido. Los resultados se hallan indeleblemente grabados en las formas espaciales de nuestras ciudades, caracterizadas cada vez más por fragmentos fortificados, comunidades valladas y espacios públicos privatizados sometidos a constante vigilancia.... Bajo estas condiciones, los ideales de identidad urbana, ciudadanía y pertenencia -ya amenazados por la difusión del malestar de la ética neoliberal- resultan mucho más difíciles de sostener [5, p. 32].

Este autor [5] nos muestra varios ejemplos de desalojo de familias, tanto en Seúl en 1990, como en Bombay, donde millones de personas son expulsadas violentamente de terrenos sin títulos de propiedad de gran valor, pero cuya permanencia en algunos casos trascendía varias generaciones. En el caso de todas estas familias ilegales los tribunales no accedieron a otorgarles compensación, a pesar de que se supone que el Estado debe velar por el derecho de bienestar y vivienda [5, p. 35].

El mismo menciona [5]: "La democratización de ese derecho y la construcción de un amplio movimiento social para hacerlo realidad son imprescindibles si los desposeídos han de recuperar el control sobre la ciudad del que durante tanto tiempo han estado privados, y desean instituir nuevos modos de urbanización" [5, p. 39].

Finalmente, nos explica [5]:

La urbanización, podemos concluir, ha desempeñado un papel crucial en la absorción de los excedentes de capital, siempre a una escala geográfica cada vez mayor, pero al precio de un proceso impresionante de destrucción creativa que ha desposeído a las masas de todo derecho a la ciudad, cualesquiera que sean éstos [5, p. 36].

\section{Resultados}

A partir de las argumentaciones de diferentes autores de diversas disciplinas y la ejemplificación de estudios de caso, podemos resumir algunas consecuencias del neoliberalismo en el ámbito espacial:

- La concepción del paisaje y las áreas naturales como mercancía.

- La globalización de las ciudades con la inserción de las mismas tipologías urbanas y arquitectónicas sin importar el contexto e incluyendo los mismos edificios comerciales.

- La aparición de los centros comerciales "no lugares", como los nuevos templos religiosos.

- El aumento de la desigualdad generando ciudades fragmentadas en fortificaciones, comunidades valladas y espacios públicos privatizados.

- Propiedad privada por encima del espacio público.

- Disminución del derecho a la ciudad.

Los retos a estas problemáticas son enormes, y necesitan de mucho trabajo multidisciplinario para generar alternativas viables. Algunos de estos retos relacionados con el diseño de la ciudad y el paisaje son:

- Diseño que considere la vida de la naturaleza a pesar de la presión ideológica del sistema. 
- Diseño que considere la particularidad de cada lugar, evitando soluciones estandarizadas.

- Diseño que considere la diversidad social y natural, así como el cambio climático.

- Aumento del derecho a la ciudad y al paisaje de todos los seres vivos.

\section{Alternativas}

\section{Recuperación de paradigmas olvidados y nuevos paradigmas emergentes}

Durante miles de años las diferentes culturas de nuestros antepasados compartieron una visión similar de su relación con el cosmos, la tierra y el resto de criaturas vivientes. Era una visión del mundo que no consideraba la humanidad como la raza dominante que utilizaba a la naturaleza para sus propios fines, sino como un habitante más de esta parte hermosa y única del universo. Así pues, nuestros antecesores respetaban y honraban a las fuerzas primitivas -el aire, la tierra, el agua y el fuego- que configuraban su mundo, buscando siempre la armonía con ellas. Intentaban armonizar su mundo interior de creencias culturales con las fuerzas espirituales que percibían a su alrededor, para asegurarse su lugar en este mundo y en el mundo del más allá. El refugio, tanto para los vivos como para los muertos estaba impregnado de simbolismo. Este simbolismo, que conectaba los objetos físicos con el plano espiritual, encontraba su expresión en las formas arquetípicas de construcción de casi todas las culturas.

La carta del jefe siux Seattle, testamento ecológico, muestra una visión de mundo totalmente opuesta al de los colonizadores ingleses:

"La tierra no pertenece al hombre, el hombre pertenece a la tierra. Todas las cosas están conectadas, como la sangre que une a una familia. Lo que le ocurre a la tierra les ocurre a los hijos de la tierra. El hombre no tejió la telaraña de la vida, es sólo un hilo. Cualquier cosa que haga a la telaraña se la hace a sí mismo" [11, p. 50].

Para Vandana Shiva [11] física, filósofa, ecofeminista y escritora india, en las culturas tribales y agrarias la identidad cultural y religiosa se deriva de la tierra. El suelo no es "un mero factor de producción", sino el alma de la sociedad, además personaliza el hogar espiritual y religioso de la mayoría de las culturas y representa todas las formas de sustento. El suelo es el espacio cultural y espiritual en el que se constituye la memoria, el mito, la historia y las canciones que componen la vida diaria.

El acercamiento a la naturaleza que considera el suelo como un elemento materno y los seres humanos como frutos del mismo y no como propietarios, ha sido y es universal, a pesar de que se ha sacrificado en todas partes como si representase una visión local y sin interés. El colonialismo transformó la tierra y el suelo que eran cuna natural de la vida y una fuente de sustento para sus habitantes; lo convirtió en una propiedad privada para ser comprada, vendida y conquistada. El desarrollo continuó lo que el colonialismo no pudo terminar. Transformó a los seres humanos de invitados en depredadores.

En muchas comunidades indígenas los individuos no tienen propiedad privada. Toda la tribu es responsable de la tierra que ocupa. La comunidad no incluye sólo a los miembros vivos, sino también a los ancestros y a las generaciones futuras. El suelo no es un concepto territorial, no define un espacio cartográfico sobre un mapa. En el caso de Costa Rica, es posible encontrar este fenómeno en los diferentes territorios indígenas, en donde por lo general no existen verjas entre las viviendas. Los pobladores saben cuáles son sus gallinas que corren libremente por todo el territorio, sin necesidad de segregar los espacios. Lamentablemente, se han dado un sin número de casos violentos en donde grupos de "no indígenas", se apropian de estas tierras. 
Claramente, una de las alternativas más importantes para el diseño de las ciudades y del paisaje, se vislumbra desde el cambio de paradigma, desde la compresión holística del territorio y sus habitantes. Para Sánchez [1], "el nuevo paradigma sienta las bases de una revolución científica basada en una percepción existencial radicada en una ecología profunda, término atribuido a Naess (1973), el cual sostenía que los seres humanos, al igual que todos los sistemas vivos, coexisten y se automantienen a través de una red de relaciones de interacción e interdependencia" [1, p. 20]. Para este autor, este nuevo paradigma impregna un profundo impacto en la educación, la pedagogía, la experiencia humana y la espiritualidad. A diferencia del viejo paradigma, no se limita al conocimiento del territorio sino que apela a la comprensión de la naturaleza de la vida y reconoce que el todo es más que la suma de las partes [1, p. 20].

\section{Diseño como bien común}

El papel del diseño dentro de los sistemas económicos modernos puede tomar muchas formas y generar resultados a menudo inesperados, con consecuencias que pueden ser significativamente mejores o peores que los planeados originalmente. Este tema fue uno de los 6 temas principales tratados en el Congreso internacional de la Cumbre Mundial de Diseño "International Congress of the World Design Summit", celebrado en octubre del 2017, en la ciudad de Montreal, bajo el lema 10 días para cambiar el mundo. Desde esta perspectiva, nos preguntamos ¿cuál es el valor del diseño, dentro de la producción de bienes y el desarrollo de la sociedad como un todo?

Si bien el diseño se puede utilizar como mercancía, también se puede usar para el bien común, lo que implica una voz de diseño más político, impulsada por valores e ideales, en lugar de un propósito exclusivamente monetario, regido por el Dios neoliberal.

Los humanos son parte de la naturaleza y, como tales, son tan frágiles como nuestro entorno de vida. Más allá de responder a emergencias y desastres o condiciones inmediatas, las disciplinas de diseño también pueden ofrecer enfoques más amplios y sostenibles para dar forma al mundo a largo plazo. Ir más allá de las necesidades a corto plazo, impulsadas por el mercado, puede permitir a los diseñadores abandonar las convenciones, ver su trabajo en una escala diferente y convertirse en agentes de cambio que pueden generar alternativas al status quo [12].

Anne Marie Collins e Isabelle Giasson [13] mostraron en este congreso, su ponencia "Innovative parklets in Montréal: Good Design is Good Business". Se presentaron los diseños de pequeños espacios públicos creados como un servicio, en donde en algunos casos era posible la venta de productos, en el distrito de Plateau-Mont-Royal en Montreal. Expusieron algunos ejemplos de antes y después de la inserción de estos espacios que incorporan el diseño de mobiliario y una buena accesibilidad, donde queda en evidencia cómo los negocios que están relacionados espacialmente aumentan sus ventas. Concluyen que el buen diseño sí es bueno para los negocios. Para estas diseñadoras, la clave para el éxito fue la evaluación de riesgos, la buena inversión, la sociabilidad con los usuarios y los clientes, así como el valor estético.

En el diseño de paisaje por lo general los grandes inversionistas que realizan proyectos de urbanización, muchas veces compran el terreno, realizan las construcciones y en una etapa final llaman al diseñador del paisaje para que "mejore" los espacios externos residuales. Esto es sin duda, una mala inversión, pues el paisajista tiene las herramientas para elegir el mejor terreno según el tipo de proyecto y la visión de las áreas verdes a proteger. En su defecto, la inversión se multiplica si se debe volver a reforestar, o rediseñar espacios por no ser concebidos desde un inicio.

No obstante, no se aprovecha la experiencia de este profesional que comprende el contexto y que hubiese podido aportar recomendaciones desde la compra del terreno. Ya se han hecho diversos estudios en el aporte económico y social que tiene la inserción del verde en la ciudad, 
que mejora la calidad de vida. Desde este punto de vista los diferentes tipos de diseño y la experiencia del profesional sí tienen un valor económico y social. Los diseñadores tienen el conocimiento y las habilidades para informar el proceso de toma de decisiones identificando y enmarcando los problemas, lo que está por encima y más allá de su capacidad de resolución técnica simple.

Los métodos innovadores desafían las mentalidades existentes y brindan alternativas nuevas y valiosas para visualizar soluciones de diseño. Alejando Aravena, arquitecto chileno junto a su equipo elemental, incorporó un diseño innovador de vivienda situado en lquique, en donde rediseñó un espacio en hacinamiento invadido de viviendas informales sin luz eléctrica, en una propuesta que permitía el diseño participativo y la ampliación de los espacios conforme los usuarios tuviesen el dinero (figuras 7 y 8 ).

La participación no hubiese sido tan importante sin un planeamiento previo por parte de los profesionales para prever ampliaciones diversas y diseñar espacios neutrales. De esta manera, la inversión del estado de aproximadamente 7500 dólares, más la de los propietarios en 750 dólares por vivienda generó edificaciones terminadas calculadas en el mercado en 20000 dólares, en más del doble de la inversión. El interés fundamental del equipo de Aravena fue maximizar el uso de los recursos públicos, incorporando el diseño de la incrementalidad [14, p. 190, 191].

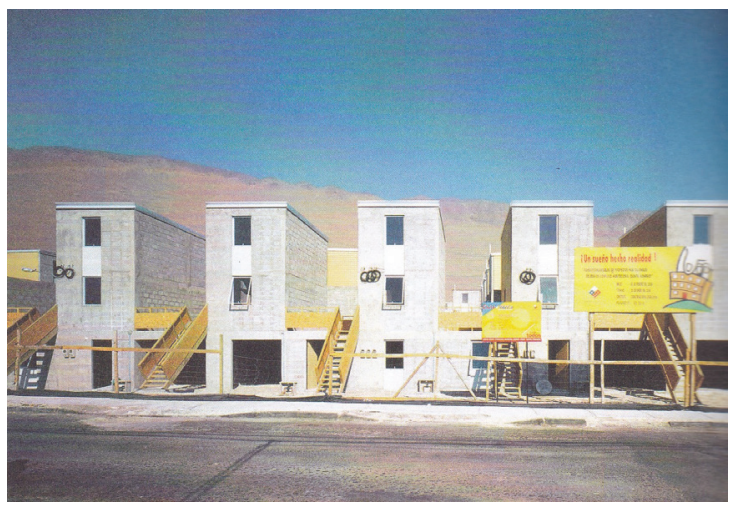

Figura 7. Conjunto habitacional Quinta Monroy en diciembre 2004. Fuente: [14]

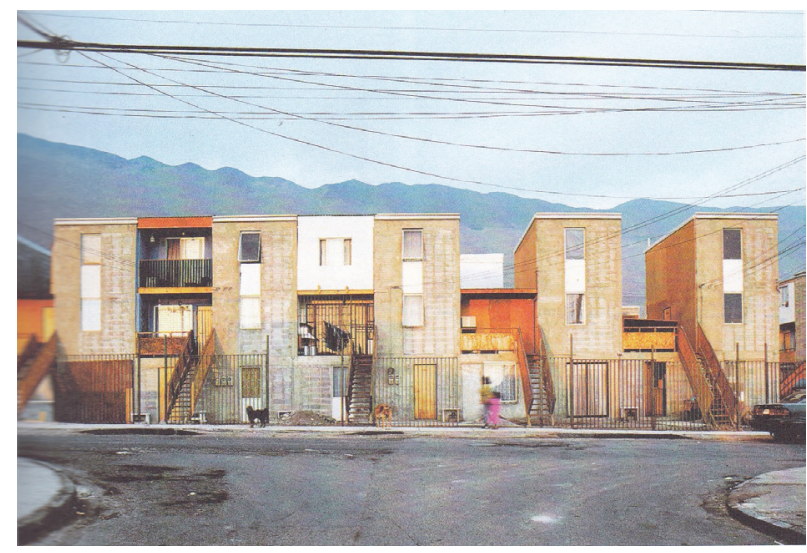

Figura 8. Conjunto habitacional Quinta Monroy en junio 2006. Fuente: [14] 


\section{Rescate de saberes locales adaptados al contexto}

El diseño depende así, de la forma de pensar y de ver el mundo del diseñador y representa un conjunto de posturas conceptuales capaces de generar cambios e innovaciones. Con la crisis del movimiento moderno se comienza a reinterpretar la historia de la arquitectura, se estudia la ciudad tradicional para recuperar la dimensión cultural y colectiva de la misma. En los años 70's con Rafael Moneo se impulsa rescatar la memoria colectiva. Se comienzan a implementar obras de arte contemporáneas en espacio público. La idea de imagen, símbolo, memoria y sueños es la superposición de lo que estructura la ciudad. La ciudad se concibe como un lugar de prácticas rituales, de la tensión y del multiculturalismo.

La síntesis entre el pasado y el presente ha sido la gran preocupación de muchos arquitectos de los países en vías de desarrollo. Mientras la sociedad industrial occidental ha generado conceptos de arquitectura internacional, tecnología moderna y nuevos materiales para construir bloques de apartamentos, aeropuertos, fábricas y grandes hoteles a menudo inadecuados para las condiciones sociales y climáticas del lugar, existen arraigadas tradiciones culturales de construcción autóctona que utilizan el conocimiento, las formas y los materiales vernáculos que ya han demostrado adaptarse perfectamente a las características del lugar durante miles de años.

La arquitectura y el paisajismo latinoamericano contemporáneo son un gran ejemplo de esta nueva preocupación del diseño por ligarse a la historia. La Tercera generación Moderna de arquitectos tales como Louis Kahn, Luis Barragán, Lina Bo Bardi y otros rechazan el formalismo y manierismo del estilo internacional. Estos arquitectos proponían una relación histórica con el proyecto contemporáneo y una estrecha relación entre la realidad, lo vernáculo y el usuario. Para ellos era fundamental crear una simbiosis entre tradición y modernidad, arquitectura y arte relacionadas con el arte popular, folclorismo y el populismo.

La arquitectura basada en las culturas y tradiciones refleja las preocupaciones y esperanzas contemporáneas en transformar los modelos del pasado para que actúen como catalizador para el futuro. Arquitectura y arquitectura del paisaje no pueden ser un dogma rígido sino un proyecto vivo, ecológico y orgánico que tenga un sentido armónico con el medio natural basado en la experiencia y el sentido común, para reconectar el diseño moderno con sus culturas tradicionales. La corriente ideal es aquella que combina el conocimiento indígena y el eco diseño con una gran fuerza y colorido, anunciando el despertar de la arquitectura natural. El manejo adecuado del entorno: materiales locales y formas tradicionales, proporcionan el bienestar y tranquilidad lograda de estructuras sencillas comprendiendo y utilizando las propiedades físicas naturales del calor, el viento y el agua como: los controles ambientales naturales.

\section{Diseño resiliente, holístico y multiescalar}

Para la construcción se utiliza una cantidad enorme de energía llamada la "energía incluida" de los materiales. Los estudios de impacto medioambiental dan a conocer el efecto destructivo de estos procesos de producción. Sin embargo, no es suficiente simplemente reducir el consumo de energía, agua y materiales e incentivar el ahorro de energía en los procesos constructivos. Se debe comenzar a pensar en diseñar ciudades y edificios resilientes. La resiliencia urbana se define como "la resistencia de un sistema total que absorbe perturbaciones, se adapta a ellas y se organiza para recobrar un equilibrio similar o adquirir uno diferente a la situación previa al desastre" [15, p. 29].

Como la medicina preventiva, que se preocupa más por el equilibrio de todo el cuerpo que por curar los síntomas de la enfermedad; el diseño de la arquitectura y la ciudad, debe considerar 
el cambio climático. De esta forma, se deben realizar proyecciones hacia el futuro considerando el incremento de tormentas, sequías, crecimiento de mareas, entre otros.

Autosuficiencia en consumo de energía, diversidad creativa y un enfoque global son las consignas de una conciencia ecológica más profunda. Como se explicó anteriormente, desde la visión del nuevo paradigma ecológico, es preciso que el diseñador conciba su intervención como parte de un todo, en donde su propuesta va a tener repercusiones sociales y ambientales, locales y globales. De esta manera, en el diseño de las ciudades debe estar presente el elemento de continuidad ecológica, por medio de protección de parches verdes y corredores biológicos que los conecten así como la incorporación de la infraestructura verde y azul. Esta última ha sido considerada una herramienta de planificación ambiental clave para el diseño resiliente. En Costa Rica, en los últimos años, la conservación de las áreas naturales va incorporando estrategias alentadoras como la protección de los corredores biológicos naturales, y más recientemente la creación de la figura de los Corredores Biológicos Interurbanos (CBI) con el Decreto Ejecutivo, No. 40043 del año 2017. Poco a poco se van gestando pequeños cambios en la mancha de concreto que alberga gran parte de nuestras ciudades.

\section{Conclusiones y/o recomendaciones (discusión)}

Según Franz Hinkelammert [1], la religión del mercado, desde el fundamentalismo de la política de maximización de las tasas de crecimiento, "niega enfáticamente y religiosamente la legitimidad del intento de parar este proceso de destrucción en curso" [3, p. 59]. La catástrofe y la autodestrucción resulta ser más rentable que la concientización. "Todos aquellos que sigan teniendo en la cabeza a otro mundo posible en esta tierra son ahora considerados partidarios del anticristo" [3, p. 52]. Gabriel Liceaga, nos expone la urgencia hacia la creación de "nuevos dioses si es que desea sobrevivir" [16, p. 251].

Para Franz Hinkelammert [1], el criterio de discernimiento de las religiones es el "significado que tiene una religión determinada sobre la praxis humana" [3, p. 63]. Se debe dar un giro a las creencias religiosas y a nuestra manera de actuar, de conformar sociedad y espacio público: Es preciso defender la ética de la vida frente a la religión neoliberal del mercado [3, p. 63].

Es por esto que dentro de las alternativas, se planteó un cambio de paradigma urgente, así como la posibilidad de utilizar el diseño como bien común, que incorpore el rescate de saberes locales adaptados al contexto. Se propone el diseño resiliente inmerso en la visión holística con estrategias como la infraestructura verde y azul, y la conectividad ecológica por medio de los corredores biológicos. Se debe rescatar la visión multiescalar del diseño y visualizar el aporte ecológico que generan las propuestas arquitectónicas y de paisaje, inmersas en un sistema de conectividad ecológico más grande.

Para este cambio de mentalidad deberíamos primero considerar nuestro hábitat no solo como un lugar donde viven los humanos, sino un lugar donde vivimos en compañía de otras especies. Todo en la naturaleza está interconectado, constituida por ecosistemas continuos, autorreguladores, regenerativos y sostenibles. Todos los procesos naturales que tienen lugar dentro de ellos son parte de un ecociclo donde los desechos de un componente se convierten en materia prima para el siguiente. Estos se relacionan a su vez con los ciclos globales de la energía, el aire y el agua. La naturaleza, además de mantener intacto su "capital" lo llega a incrementar.

Cualquier especie de la naturaleza está interrelacionada con las otras; un pequeño cambio puede afectar al sistema y crear un gran efecto adverso (teoría del caos). Las vibraciones del ala de una mariposa, por ejemplo, pueden causar una reacción en cadena que conlleve finalmente a una tormenta en una selva en la otra punta del mundo. De esta forma, un edificio 
puede causar grandes males a un ecosistema; el edificio se convierte en un parásito de la naturaleza, así como el mismo ser humano. El tema de la armonía con la naturaleza no es un deseo meramente sentimental o nostálgico, sino una necesidad práctica para que la arquitectura y el paisaje diseñado sean parte de un ecosistema como lo mencionaba el jefe siux y no nos sumerjamos en el autosuicidio colectivo.

\section{Agradecimientos}

Se agradece al profesor Franz Hinkelammert, por sus enseñanzas. Asimismo, al doctorado en Estudios de la Sociedad y la Cultura de la Universidad de Costa Rica por incentivar los enfoques y aprendizajes multidisciplinares. Además, a la Comisión de Investigación y Extensión de la Escuela de Arquitectura y Urbanismo del Instituto Tecnológico por impulsar la compilación de estos trabajos.

\section{Referencias}

[1] G. Sánchez Chacón. "Percepción sistémica de la innovación educativa: Reflexiones desde el nuevo paradigma científico." Ensayos pedagógicos, vol. 11, no. 1, pp. 17-39, 2016.

[2] F. Hinkelammert. "La estrategia del suicidio global: Una economía mundial con maximización de las tasas de crecimiento", no publicado, 2007.

[3] F. Hinkelammert. "La crítica de la religión neoliberal del mercado y los derechos humanos," en La religión neoliberal del mercado y los derechos humanos. 1ra ed. San José, Costa Rica: Editorial Arlekín, 2017, pp. 21-68.

[4] H. Marcuse. El hombre unidimensional. Ensayo sobre la ideología en la Sociedad industrial avanzada. Barcelona, España: Editorial Planeta de Agostini, 1993.

[5] D. Harvey."El derecho a la Ciudad”. New Left Review, vol. 53, pp. 23-39, 2008. Recuperado de: http://newleftreview.es/authors/david-harvey

[6] A. Césaire. (s.f.). Discurso sobre el Colonialismo (fragmento). pp 13-43. Recuperado de: http://www.ram-wan. net/restrepo/decolonial/4-cesaire-discurso\%20sobre\%20el\%20colonialismo.pdf

[7] B. Sarlo. (Mayo / Junio del 2006). El Centro Comercial. Jirafa con tacones (11). Recuperado de: http://www. fusion3.com.ar/lajirafacontacones/numero11/N11-COMUNICACION.pdf

[8] Saint Joseph's oratory of Mount Royal. Recuperado de: https://www.saint-joseph.org/en/place-of-welcome/ourgift-shops/

[9] M. Gravari-Barbas. Aménager la ville par la culture et le tourisme. Paris, Francia: Éditions du Moniteur, 2013.

[10] J. Vergara Estévez. "La crisis de la teoría neoliberal," en La religión neoliberal del mercado y los derechos humanos. 1ra ed. San José, Costa Rica: Editorial Arlekín, 2017, pp. 191-206.

[11] V. Shiva. "Ecofeminismo desde el Tercer Mundo" en Nueva conciencia. Plenitud personal y equilibrio planetario para el siglo XXI. Barcelona, España: Editorial Integral, 1994.

[12] World Design Summit, "108 Topics", presentado en el World Design Summit, Montreal, Canadá. 2017.

[13] A. M. Collins y I. Giasson. "Innovative parklets in Montréal: Good Design is Good Business", presentado en el World Design Summit. Montreal, Canadá. 2017.

[14] A. Aravena y A. Lacobelli. ELEMENTAL, Manual de vivienda incremental y diseño participativo. Berlín, Alemania: Jatje Cantz, 2016.

[15] L. Bertoux y D. González. "Vulnerabilidad y Resiliencia Urbana Frente al Cambio Climático: El Caso de la Zona Metropolitana de Guadalajara, México." Urbano, vol 18, no. 31, pp. 24-31. Recuperado de: http:// search.ebscohost.com.ezproxy.sibdi.ucr.ac.cr:2048/login.aspx?direct=true\&db=fua\&AN=110614247\&site=eh ost-live\&scope $=$ site

[16] G. Liceaga. "Llamando a Nuevos Diosos," en La religión neoliberal del mercado y los derechos humanos. 1ra ed. San José, Costa Rica: Editorial Arlekín, 2017, pp. 250-265. 